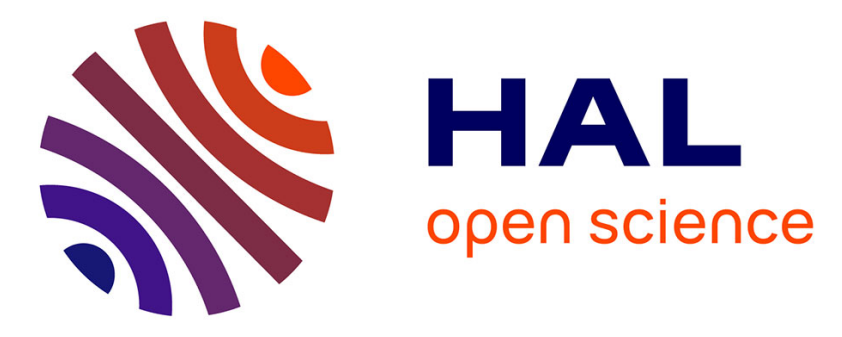

\title{
Comparison of Two Retrieval Techniques for Ice Particle Mass from in-situ Measurements: Implication for Particle Effective Density and Median Mass Diameter
}

Pierre Coutris, Delphine Leroy, Emmanuel Fontaine Fontaine, Alfons Schwarzenboeck, John Strapp, Alice Grandin

\section{To cite this version:}

Pierre Coutris, Delphine Leroy, Emmanuel Fontaine Fontaine, Alfons Schwarzenboeck, John Strapp, et al. Comparison of Two Retrieval Techniques for Ice Particle Mass from in-situ Measurements: Implication for Particle Effective Density and Median Mass Diameter. AIAA Journal, 2017, 10.2514/6.20174245. hal-01980984

\author{
HAL Id: hal-01980984 \\ https://hal.science/hal-01980984
}

Submitted on 31 Jan 2022

HAL is a multi-disciplinary open access archive for the deposit and dissemination of scientific research documents, whether they are published or not. The documents may come from teaching and research institutions in France or abroad, or from public or private research centers.
L'archive ouverte pluridisciplinaire HAL, est destinée au dépôt et à la diffusion de documents scientifiques de niveau recherche, publiés ou non, émanant des établissements d'enseignement et de recherche français ou étrangers, des laboratoires publics ou privés.

\section{(ㄷ)(1) $\$$}

Distributed under a Creative Commons Attribution - NonCommerciall 4.0 International 


\title{
Comparison of two retrieval techniques for ice particle mass from in-situ measurements: implication for particle effective density and Median Mass Diameter
}

\author{
Pierre Coutris ${ }^{1}$, Delphine Leroy ${ }^{2}$, Emmanuel Fontaine $^{3,4}$ and Alfons Schwarzenboeck ${ }^{5}$ \\ Laboratoire de Météorologie Physique, CNRS/UCA, Aubière, France \\ and \\ J. Walter Strapp 6 \\ Met Analytics Inc., Toronto, Ontario, Canada \\ and \\ Alice Calmels ${ }^{7}$ \\ Airbus Operations SAS, Toulouse, France
}

\begin{abstract}
Ice particles in clouds are a known threat to commercial aviation. They can form areas with high ice water content at cruise altitudes where severe icing conditions may be sustained and not detected with current on-board technologies. In this article, a comparative study between two ice particle mass retrieval methods is presented. Both methods use in-situ measurements of the Particle Size Distribution (PSD) and Ice Water Content (IWC) as input to establish mass-diameter relationships (henceforth $m-D$ ). The first method follows the classical approach where the form of the $m-D$ relationship is limited to power laws. The second method is based on an inverse problem approach: it leverages optimal use of in-situ measurements to waive the power law constraint. Both methods are tested on an in-situ measurement dataset collected during one research flight in an oceanic Mesoscale Convective System (MCS) with measured IWC values frequently exceeding $1.0 \mathrm{~g} . \mathrm{m}^{-3}$. This flight was carried out in Darwin (Australia) area during the High Altitude Ice Crystals/High Ice Water Content 2014 international field campaign. Results show significant differences in crystal masses retrieved from both methods. The first outcome of the comparison is that IWC values calculated from the non-classical method are significantly closer to the measured IWC values than those calculated from the classical approach (the overall error is decreased by almost a factor 2). Another advantage of the non-classical approach is the increased latitude in the retrieval process to actually capture some size dependent microphysical processes. Preliminary results reveal different regimes in the variation of particle effective density with size. These variations are not captured by the classical mass retrieval methods where the $m-D$ power law assumption restricts the shape of effective density versus size to a strictly decreasing polynomial curve. The Median Mass Diameter values (MMD) retrieved along flight path with both methods are found to differ: MMDs calculated from the inverse problem approach are consistently $20 \%$ smaller than those produced by the classical power law.
\end{abstract}

\footnotetext{
${ }^{1} \mathrm{PhD}$ student, LaMP (CNRS/UBP), 4 avenue Blaise Pascal, TSA 60026,63178 Aubière Cedex, France.

${ }^{2}$ Cloud physicist, LaMP (CNRS/UBP), 4 avenue Blaise Pascal, TSA 60026,63178 Aubière Cedex, France.

${ }^{3}$ Postdoctoral researcher, LaMP (CNRS/UBP), 4 avenue Blaise Pascal, TSA 60026,63178 Aubière Cedex, France.

${ }^{4}$ Postdoctoral researcher, Meteorology Department, University of Reading, United Kingdom (current position).

${ }^{5}$ Professor, LaMP (CNRS/UBP), 4 avenue Blaise Pascal, TSA 60026,63178 Aubière Cedex, France.

${ }^{6}$ Physical Scientist, Met Analytics Inc., Aurora, ON, Canada L4G4Y1

${ }^{7}$ Ice Protection System Expert, AIRBUS S.A.S., P.O. Box M0141/6, 31060 Toulouse cedex 03, France
} 


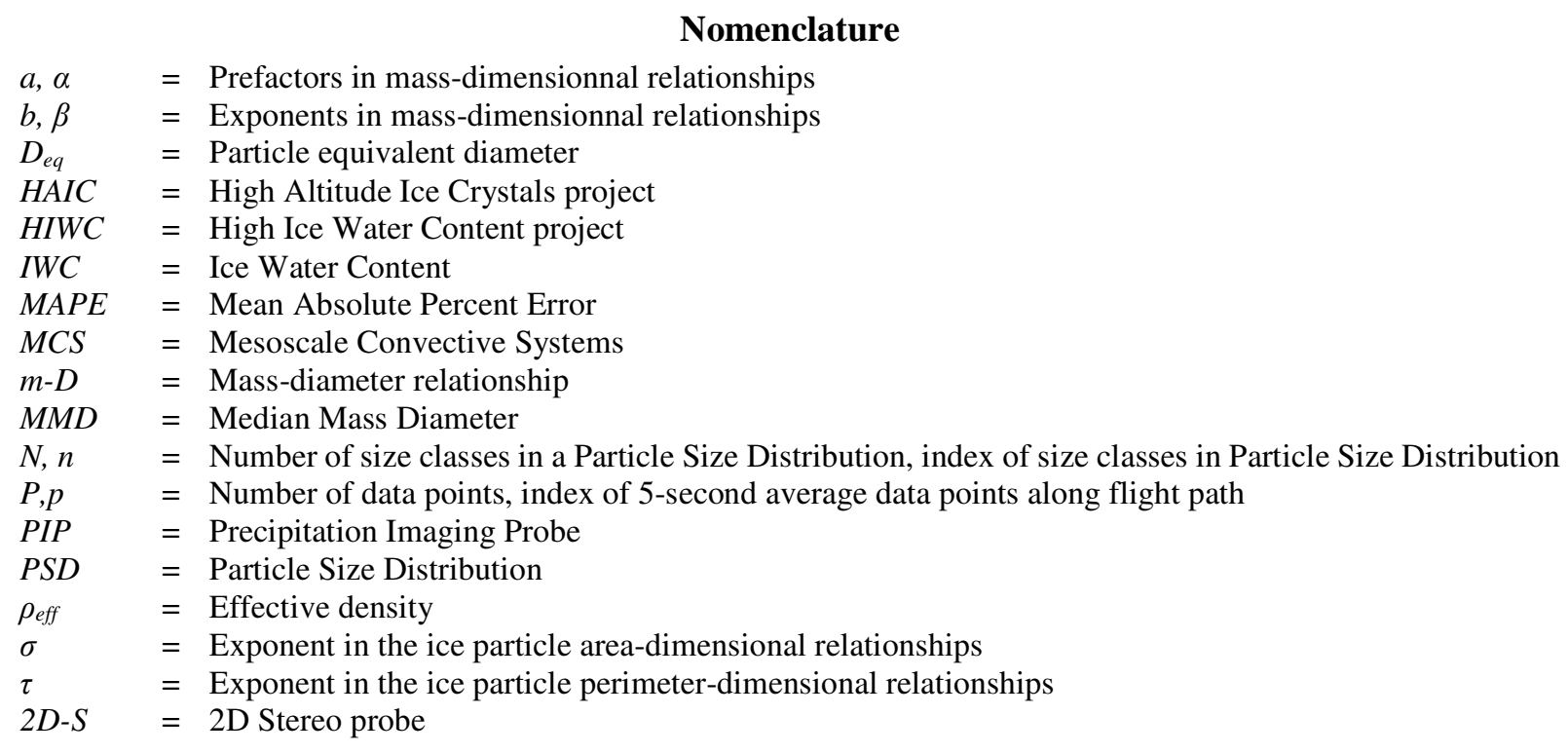

\section{Introduction}

Tee particles in cloud are a known icing threat to commercial aviation ${ }^{1}$ when present in large number and mass concentration during all phases of flight above the freezing level. Natural atmospheric phenomena such as the uplift of low level air with high water vapor content to the upper troposphere generally produce considerable concentrations of ice particles ranging from few tens of micrometers up to several millimeters in size. High ice water content areas resulting from these large concentrations of ice crystals may have adverse effects on aircraft: ice crystal icing events in engines and air data probes have been reported in such areas ${ }^{2}$, while these severe icing areas remain undetectable with current on-board technologies due to the low cloud reflectivity ${ }^{3-4}$.

In 2004, the Engine Harmonization Working Group (EHWG), composed of aircraft engine manufacturers and airframers, aviation regulators, and government agencies involved in aircraft icing research, was formed to investigate issues related to mixed-phase and glaciated cloud icing. The issue of ice crystal icing became the central focus. The EHWG examined current regulatory guidelines, and concluded they had unknown accuracy and were no longer traceable. The EHWG proposed a new interim ice crystal envelope "Appendix D" based on engine power-loss event data, downscaled theoretical maximum expected adiabatic water content values, and the most extensive data available at the time from the 1950s. The interim envelope was part of a new certification rule for supercooled large drop, mixed phase, and ice crystal icing conditions that was put into law by the FAA and EASA in 2015. The rule also contained guidelines for ice particle size based on the limited amount of information available at the time. The EHWG further recommended new flight campaigns with in-situ measurements to assess the interim Appendix D envelope. Subsequently, the in-situ data have been collected in 3 flight campaigns, the first two from an international collaboration of the High Altitude Ice Crystals ${ }^{6}$ (HAIC) and High Ice Water Content ${ }^{7}$ (HIWC) projects started in 2012 , and the third from an independent HIWC project focused on pilot radar technology. The resulting data, mostly from high IWC areas in tropical Mesoscale Convective Systems, are now being studied as part of the Appendix D assessment, and for general research on ice crystal icing. The new Appendix D envelope will be used to develop means of compliance for the certification of engines and other aircraft subsystems. Another objective of the European HAIC project is to improve understanding of the ice crystal icing phenomena through the development of both experimental devices and numerical models of ice accretion. In this context, another desirable outcome of the HAIC/HIWC in-situ measurement data set is the retrieval of ice particle mass-related properties that could be very useful for both ice particles trajectory and accretion models, and icing wind tunnel calibration.

Different techniques to retrieve ice particle mass-related properties from in-situ measurements have been published over the last few decades. In this paper, two mass retrieval methods, one following the state-of-the-art power law approach and the other based on a recently developed inverse problem approach, are applied to a set of in-situ measurements extracted from the HAIC/HIWC dataset. The dataset is presented in section II and the two methods are introduced in section III. In section IV, the results are compared with emphasis on two quantities: the ice particle effective density ( $\left.\rho_{\mathrm{eff}}\right)$ and the Median Mass Diameter (MMD). 


\section{HAIC/HIWC in-situ measurements and data processing}

The HAIC/HIWC data set was collected in deep convective clouds ranging in size from individual cumulonimbus to large Mesoscale Convective Systems (MCSs), the latter being the primary target and providing the majority of the data. The in-situ data were collected from the SAFIRE (Service de Avions Français Instrumentés pour la Recherche en Environnement) Falcon-20 (F20) aircraft in the Darwin- $2014^{8}$ campaign, and by the F20 and the National Research of Canada (NRC) Convair-580 in the Cayenne-20159 campaign.

The purpose of this technical study, being the comparison between two mass retrieval methods rather than an exhaustive analysis of the HAIC/HIWC data set, the analysis of this study is limited to the data points collected during one single flight performed on February $7^{\text {th }} 2014$ in an oceanic MCS near Broome, Australia. During this flight, labelled Darwin \#16, the F20 research aircraft flew several legs at the $-38^{\circ} \mathrm{C}$ temperature level, resulting in 21105 second average data points. In Fig. 1 the 3-hour flight pattern is superimposed on a color-enhanced infrared satellite image of the sampled MCS. The white areas in the images represent cloud tops that have reached approximately the $80{ }^{\circ} \mathrm{C}$ or colder.

The state-of-the-art instrumentation package installed on the F20 included the IsoKinetic evaporator Probe (IKP2, bulk IWC reference instrument) ${ }^{10-11}$ and two Optical Array Probes (OAP), the 2D-Stereo (2D-S $)^{12}$ and the Precipitation Imaging Probe (PIP) ${ }^{13}$.

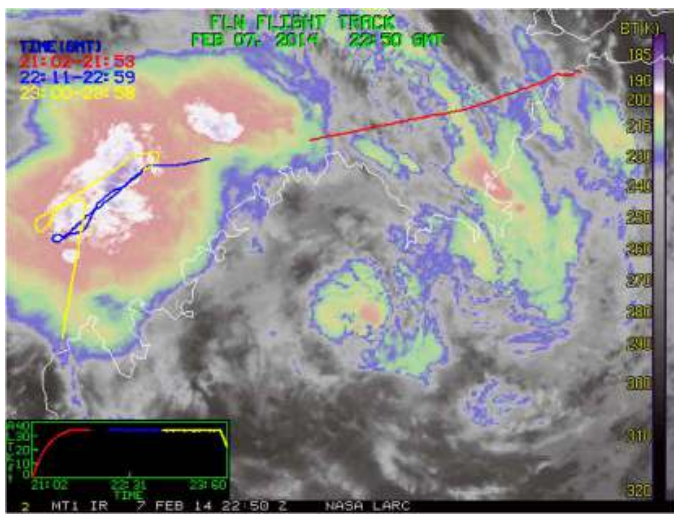

Figure 1. Satellite image of the MCS sampled during Darwin \#16 flight
IWC values were calculated by substracting background humidity from the total water vapor measured by the IKP-2 after evaporation of all condensed particles. Due to errors associated with this background humidity subtraction, data points with IWC value lower than $0.1 \mathrm{~g} \cdot \mathrm{m}^{-3}$ were discarded for this analysis. In addition, the data were restricted to periods of level flight.

The 2D-S and PIP produce monochromatic 2D images of ice particles: their size ranges are $10 \mu \mathrm{m}-1280 \mu \mathrm{m}$ and $100 \mu \mathrm{m}-6400$ $\mu \mathrm{m}$, with a resolution of $10 \mu \mathrm{m}$ and $100 \mu \mathrm{m}$ respectively. OAP images are processed so as to discard data corrupted by splashing/shattering artifacts, to correct out-of-focus images, and to reconstruct truncated particles, as detailed in ref. 14. Then images are analyzed in order to retrieve geometrical quantities of individual particles such as projected area, perimeter or maximum dimension. Particles are then binned into size classes according to a size parameter. In this study we use the equivalent area diameter $\mathrm{D}_{\text {eq }}$, defined as the diameter of a circle having the same area as the particles's shadowed pixels, and PSDs span from $10 \mu \mathrm{m}$ up to $12850 \mu \mathrm{m}$. Such a large size range is obtained by merging the 2D-S and the PIP data into a composite PSD where 2D-S data are used below $800 \mu \mathrm{m}$, PIP data above $1250 \mu \mathrm{m}$, and a weighted average of both probes data is calculated for the $800-1250 \mu \mathrm{m}$ overlap. The resulting composite PSD has 240 size bins with a bin width of $10 \mu \mathrm{m}$ from $15 \mu \mathrm{m}$ to $1250 \mu \mathrm{m}$ and a bin width of 100 $\mu \mathrm{m}$ from $1250 \mu \mathrm{m}$ to $12850 \mu \mathrm{m}$. Once all filters are applied, there are 10515 -second average coincident and collocated IWC and PSD in-situ measurements to support the comparative study. The main characteristics of this data set are summarized in Table 1:

Table 1. Characteristics of Darwin \#16 data set

\begin{tabular}{|c|c|c|c|c|c|}
\hline Flight ID & Date, Location & Cloud type & $\begin{array}{c}\text { Temperature level } \\
\text { Mean (std. dev. }) \\
(\mathrm{K})\end{array}$ & $\begin{array}{c}\text { IWC values } \\
\text { min/mean/max } \\
\left(\mathrm{g} \cdot \mathrm{m}^{-3}\right)\end{array}$ & $\begin{array}{c}\text { Data points } \\
(\#)\end{array}$ \\
\hline Darwin \#16 & $\begin{array}{c}\text { 07 } \\
\text { Broome, Australia }\end{array}$ & Oceanic MCS & $236.1(0.363)$ & $0.1 / 1.07 / 2.75$ & 1051 \\
\hline
\end{tabular}

In the following, we note $N=240$ the number of size bins and $P=1051$ the number of data points available in the Darwin \#16 set. 


\section{Mass retrieval from PSD and IWC in-situ measurements: presentation of the two methods}

The need for the size dependent parametrization of the mass of ice particles is particularly important for the development of atmospheric numerical models in which mass related properties are a key module. In order to estimate ice particle mass from in-situ measurements, many studies have been published over the last decades: one can refer to the literature review provided in ref.14 for references to state-of-the-art techniques. In summary, almost all of these methods make the assumption that $m-D$ relationship conforms to a power law. In section III.A, one of these state-ofthe-art methods is presented. It has been developed recently for the HAIC project and serves as baseline method in this comparative study. The second method uses a recently proposed non-standard approach ${ }^{15}$, in which the mass retrieval is formulated as an inverse problem, as further detailed in section III.B. The new results produced by the latter approach need to be compared to those of the standard approach to evaluate the method's efficacy and any improvements it may offer.

\section{A. Power Law Approach}

The first method (henceforth Method A) is adapted from the retrieval method published in ref. 14. The original method was selected as the reference state-of-the-art method for three reasons:

- it uses the same in-situ measurements described above (PSD, IWC) as the other method, such that there is no instrumental bias in the comparison,

- $\quad$ the $m-D$ relationships are established with PSD based on $\mathrm{D}_{\mathrm{eq}}$, as for the other method,

- $\quad$ the $m-D$ relationships were developed using the HAIC data set, i.e. for the same clouds and atmospheric conditions as the other method, such that there is no environmental bias in the comparison.

This method follows an approach classically used in the atmospheric science literature in which a power law is used to describe the dependence of ice particle mass on size. For each 5-second average data point, a relation written $m=a \cdot D^{b}$ is applied and a two-fold technique is used to compute the $(a, b)$ pair from OAP images and IWC values:

1) The exponent $b$ is calculated from $\sigma$ and $\tau$, dynamically calculated exponents of the area- and perimeterdimensionnal relationships based on real-time $2 \mathrm{D}$ imagery where: $b=1.956 \sigma-1.038 \tau$

2) The prefactor $a$ is then derived as the value that equalizes the IWC value calculated from PSD and $m-D$ relationship to the reference value measured by the IKP-2 instrument.

This method produces as many $m-D$ relationships as there are data points. To allow for a meaningful comparison of integrated IWC values with the other method, method A is adapted so that all 1051 relationships established from Darwin \#16 data points are reduced to a unique $m-D$ relationship: $m=\alpha \cdot D^{\beta}$. This is done in three steps:

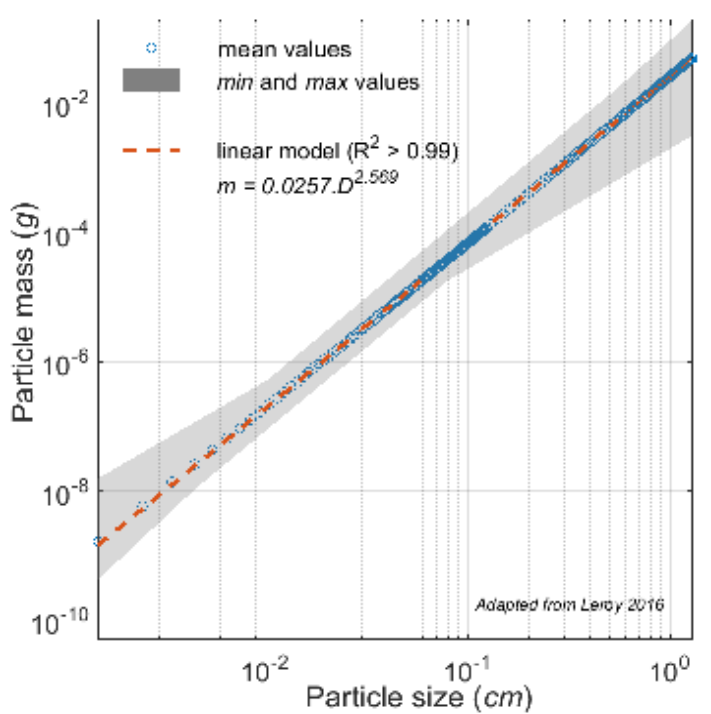

Figure 2. $m-D$ relationship found with the power law approach.
1) For each bin of the PSD, the mean mass is calculated by averaging the $P$ masses predicted by the ref. $14 m-D$ relationships:

$$
\forall n \in[1 \cdots N], \bar{m}_{n}=\bar{m}\left(D_{n}\right)=\frac{1}{P} \sum_{p=1}^{P} \alpha_{p} \cdot D_{n}^{\beta_{p}}
$$

2) The mean masses for each size bin from equation (1) $\left(\bar{m}_{1} \bar{m}_{2} \cdots \bar{m}_{N}\right)$ are plotted against size in a log-log scale.

3) A least square fitting is calculated and the two scalars $\alpha$, $\beta$ are calculated from the slope and intercept of the linear fit.

For Darwin \#16 set, we found $\alpha=0.0257 \mathrm{~g} . \mathrm{cm}^{-2.569}$ and $\beta=2.569$, hence the power-law based m-D relationship:

$$
m=0.0257 \cdot D_{e q}^{2.569}
$$


Figure 2 shows the discrete mean masses plotted against size in log-log scale, as well as the linear model. The shaded area delineates the minimum and maximum mass values found in each bin and illustrates the variability in mass that results from the 1051 different $m-D$ relationships established dynamically by the original power law technique.

\section{B. Inverse Problem Approach}

The second method (henceforth Method B) assumes that particles in a PSD bin can be approximated by a "reference mass". As a result, $N$ unknown independent masses have to be retrieved. This is done by setting a linear system of equations that relates these masses to in-situ measurements, as formally written in the matrix equation (3):

where:

$$
\text { PSD. } m=I W C
$$

$P S D$ is a $N \times P$ matrix in which 5-second average PSDs are vertically concatenated,

$m=\left(m_{1} m_{2} \cdots m_{N}\right)^{T}$ is the vector of $N$ reference masses to be retrieved. They are in ascending order such that $m_{1}$ and $m_{N}$ are the reference masses of the first (smallest particles with $D_{e q}=15 \mu m$ ) and last bin (largest particles with $D_{e q}=12800 \mu \mathrm{m}$ ), respectively,

$I W C$ is the vector of $P 5$-second average IWC values measured by the IKP-2 reference instrument.

As detailed in ref. 15, the retrieval process consists of solving the inverse problem by minimizing a composite criterion:

$$
J(m)=\|P S D \cdot m-I W C\|^{2}+\lambda \cdot R(m)
$$

where:

$\lambda$ is a regularization parameter
$R(m)$ is a regularization term

In summary, both methods take PSD and IWC in-situ measurements as input but use them in a different manner. In the first method, the power law approach relates mass and diameter with an equation, $m=0.0257 \cdot D^{2.569}$, where coefficients are derived by averaging the explicit $m-D$ power law relationships retrieved dynamically along the flight path as per ref. 14, but the mass as a function of size must vary according to the power law. In the inverse problem approach, a vector of independent size-resolved reference masses is produced, which is not dependent on any fixed relationship such as a power law. This vector is computed by solving a system of linear equations written from a set of several data points considered all at once.

\section{Results and Discussion}

\section{A. Ice particle mass and IWC retrieval}

In Fig. 3 the particle masses retrieved with the two methods are plotted against size on a log-log scale. For small particles $\left(\mathrm{D}_{\text {eq }}<500 \mu \mathrm{m}\right)$, both methods produce comparable mass values although the slope predicted by Method B is slightly higher. Mass values are almost identical within the $100<\mathrm{D}_{\mathrm{eq}}<200 \mu \mathrm{m}$ size interval. Major differences appear for particle sizes above $500 \mu \mathrm{m}$, where the two curves differ significantly. Method B reveals a noticeable transition in the $500<\mathrm{D}_{\text {eq }}<1300 \mu \mathrm{m}$ size range, where the variation of mass with size changes towards what seems to be a second regime between $1300<\mathrm{D}_{\mathrm{eq}}<12800 \mu \mathrm{m}$. In this segment, the masses retrieved with Method B are consistently smaller by a factor of 3 than those predicted with Method A. The discontinuity at about $1300 \mu \mathrm{m}$ may be instrumental, due to the switchover from data collected at $10 \mu \mathrm{m}$ resolution (2D-S) to $100 \mu \mathrm{m}$ resolution (PIP). The quality of the mass retrieval can be indirectly estimated by assessing how IWC values calculated from number PSD and the retrieved masses ( $\mathrm{IWC}_{\text {calc }}$ ) compare to the reference IWC values measured by the IKP-2 instrument. To do so, the ratio of calculated to measured IWC values is computed for each 5-sec data point and its frequency distribution is plotted in Fig. 4. 


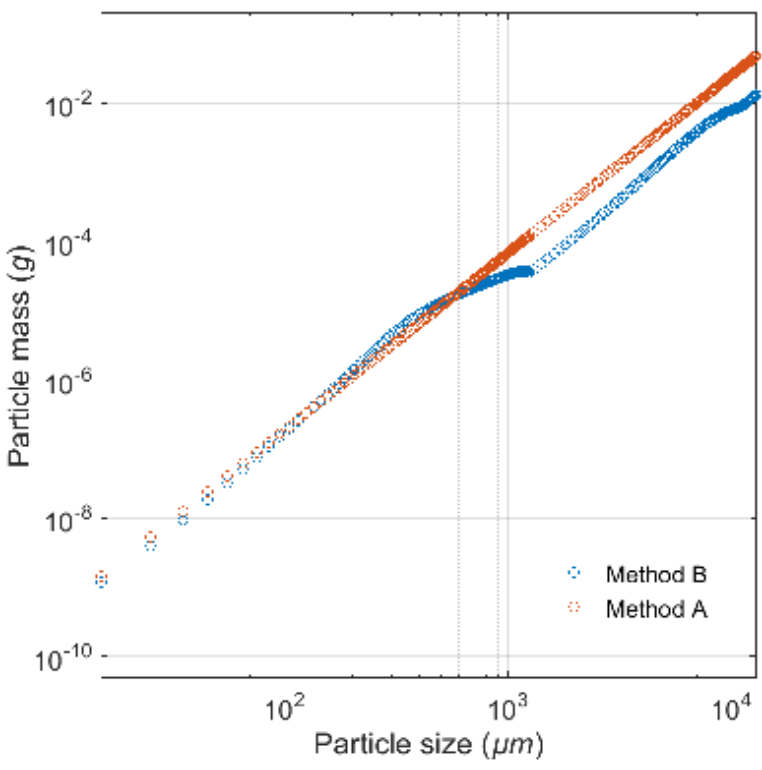

Figure 3. Particle mass against size.

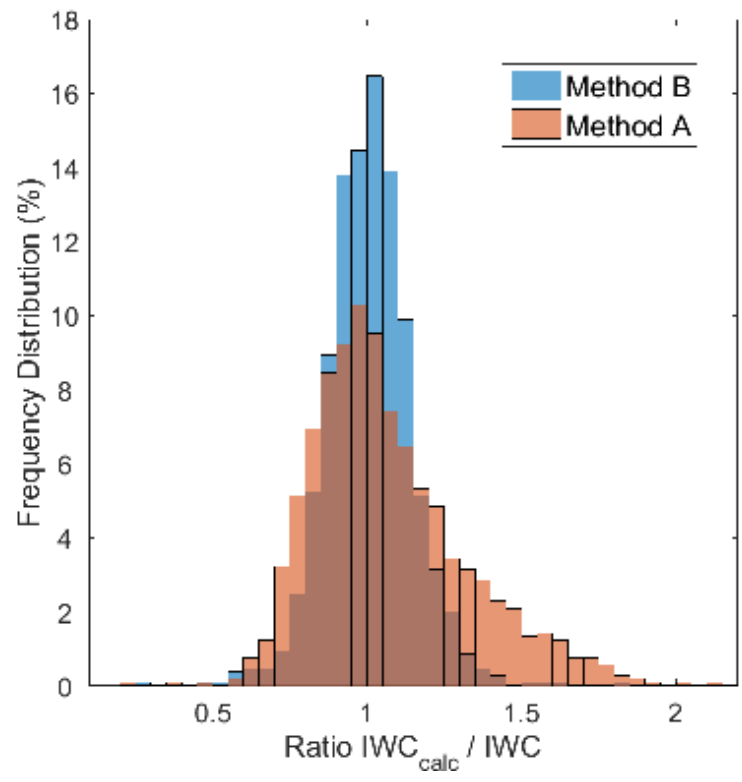

Figure 4. Accuracy of the IWC reconstruction.

The IWC calculated with Method B demonstrate a much better agreement with the measured IWC as its frequency distribution is narrower. Both Method A and B distributions are centered around unity but Method A yields a slight overestimation of IWC values (the mean of these ratio is 1.07 for Method A). In contrast, this bias is hardly noticeable in the Method B (less than 1\%). Calculation of the Mean Absolute Percent Error (MAPE), defined in Eq. (5), confirms the superior Method B results for IWC retrieval: the MAPE obtained with Method B (10.5\%) is almost half of that of Method A (19.3\%).

$$
\operatorname{MAPE}(\%)=\frac{100}{P} \sum_{p=1}^{P} \frac{\left|I W C_{c a l c, p}-I W C_{p}\right|}{I W C_{p}}
$$

\section{B. Effective density}

In the context of illustrating Method B's potential improvement in defining properties of natural ice particle populations, perhaps most striking is the comparison of the ice particle effective density retrieved by both methods. The variation of effective density with size, defined as the particle mass divided by the volume of an equivalent diameter sphere, is strongly constrained when a power law is assumed for the $m-D$ relationship: it can be derived analytically as $\rho_{\text {eff }}=\frac{6 \alpha}{\pi} D^{\beta-3}$.

By searching for independent size-resolved particle masses, the variation of effective density versus size for the Method B formulation is much less constained because it is not forced to fit within any pre-assumed $m-D$ relationship. This is clearly illustrated in Fig. 5, where the effective density computed from both methods is plotted against size. Due to the constraints of the $m-D$ relationship for Method A, its effective density is a regular polynomial curve as expected. Effective density values decrease from $0.81 \mathrm{~g} . \mathrm{cm}^{-3}$ to $0.044 \mathrm{~g} . \mathrm{cm}^{-3}$ as particle size vary from $15 \mu \mathrm{m}$ to 12.8 $\mathrm{cm}$. 


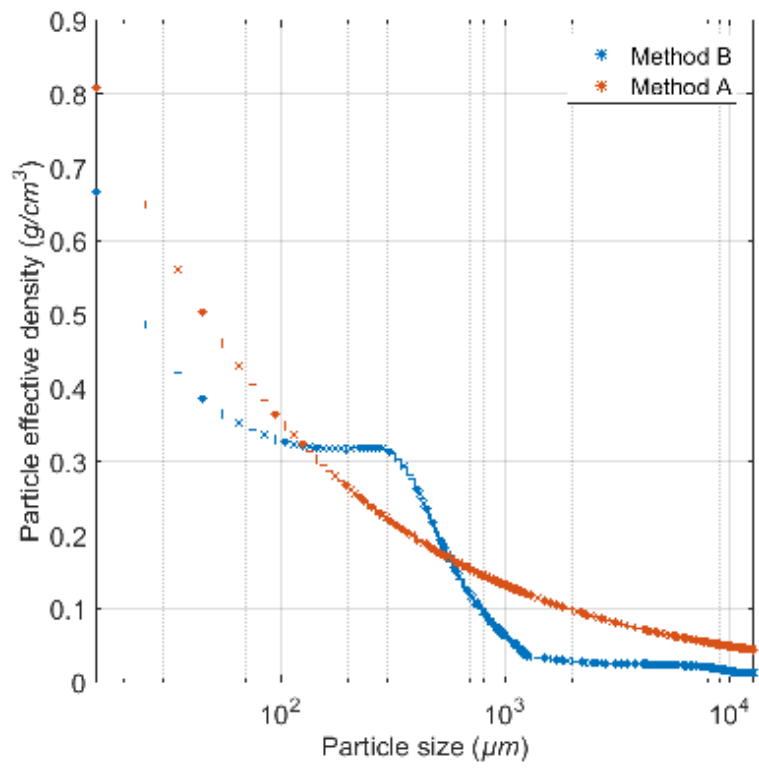

Figure 5. Particle effective density against size

In contrast, one can see that the curve produced by Method B shows pronounced variations and distinctive regimes as already noted when discussing Fig. 3. The effective density decreases from 0.67 g.cm ${ }^{-3}$ to 0.32 g.cm${ }^{3}$ as size increases from $15 \mu \mathrm{m}$ to $300 \mu \mathrm{m}$. The $300<\mathrm{D}_{\text {eq }}$ $<1300 \mu \mathrm{m}$ size interval seems to be a transition regime where the effective density of ice particles decreases markedly from $0.32 \mathrm{~g} . \mathrm{cm}^{-3}$ to $0.034 \mathrm{~g} . \mathrm{cm}^{-3}$. Then a third regime is reached for large particles $\left(D_{\mathrm{eq}}>1300 \mu \mathrm{m}\right)$, where the effective density values slowly decrease down to approximately $0.012 \mathrm{~g} . \mathrm{cm}^{-3}\left(\mathrm{D}_{\mathrm{eq}}=12.8 \mathrm{~cm}\right)$. Currently, there are a few caveats associated to these very new, but preliminary results: first sensitivity studies of the influence of the regularization term definition on Method B reveals that the effective density values computed for the smallest size bins below $300 \mu \mathrm{m}$ (and above $4000 \mu \mathrm{m}$ to a lesser extent) do vary depending on the regularization value. However effective density values calculated for $300<D_{\text {eq }}$ $<4000 \mu \mathrm{m}$ are quite insensitive to the regularization values tested. Although further investigations need to be conducted to confirm these preliminary results, the authors believe that the irregular shape of the Method B effective density curve, where quasi-constant values have been found to persist over quite wide size intervals may be more realistic than the regular polynomial curve produced by Method A. As shown in ref. 15, ice particle effective density is mostly controlled by the crystal habits, and effective density curves with plateau-like regimes have been produced with simulated crystal populations composed of different crystal types. Observation of cloud ice particle images reveal that some crystal habits can dominate particular size intervals. Such complexities of true ice crystal populations would be best captured by the less constrained Method B.

\section{Median Mass diameter}

The Median Mass Diameter (MMD) is a simple yet useful parameter to describe the microphysical properties of ice particle populations. It is defined as the diameter that splits the cumulative mass distribution in half: half the mass resides in particles with $\mathrm{D}_{\mathrm{eq}}<\mathrm{MMD}$, and the other half in particles with $\mathrm{D}_{\mathrm{eq}}>\mathrm{MMD}$. The EHWG concluded that cloud particle size may play a role in engine icing, in that smaller ice particles may produce conditions in the engine more conducive to initiating ice accretion. However, this remains a topic of debate due to the perhaps over-riding mechanical breakup of particles in the engine. The new Appendix D envelope contains particle size guidelines that were based on the limited amount of information available at the time of its creation. The flight campaign data will provide more realistic MMD values, computed using the methods described in ref. 9, that may provide superceding values to be used in establishing certification means of compliance. MMD is a key parameter in numerical models ${ }^{16}$ and experimental setups used to study ice accretion mechanisms within engine modules. Hence the need for an accurate characterization of the MMD from in-situ measurements. In this section, MMD obtained with the original method of ref. 14 are compared to those retrieved with Methods A and B described above. The three methods used to compute MMDs are again listed below ( $p$ is the sampling point index varying from 1 to $P=1051$ ):

- ref. 14 ("Leroy 2016" below): $M M D_{p}=f\left(P S D_{p}, m=a_{p} \cdot D^{b_{p}}, I W C_{\text {calc }, p} \approx I W C_{p}\right)$

- Method A (adapted from Leroy 2016): $M M D_{p}=f\left(P S D_{p}, m=0.0257 \cdot D^{2.569}, I W C_{\text {calc }, p}\right)$

- Method B (Inverse Problem approach): $M M D_{p}=f\left(P S D_{p}, m=\left(m_{1} m_{2} \cdots m_{N}\right), I W C_{c a l c, p}\right)$

Both Method A and Method B compute the MMD from the cumulative mass distribution and the independent IWC reference (measured) value of the IKP-2. The error diagram given in Fig.4 indicates that for both methods there are some points where the retrieved IWC value significantly differs from the IKP-2 reference value. For these data points, the calculation of MMD might either be impossible (if $I W C_{\text {calc }}<1 / 2 I W C$ ) or unreliable $\left(I W C_{\text {calc }} \gg I W C\right.$ ) leads to artificially large MMDs). To provide a fair comparison between both methods, the comparison is done on a subset of points for which both methods perform best: in this section, we only consider data points where the calculated $\mathrm{IWC}_{\text {calc,p }}$ values estimated from Method A and Method B match the respective $\mathrm{IWC}_{\mathrm{p}}$ measurements within $20 \%$ (632 points out of 1051). 


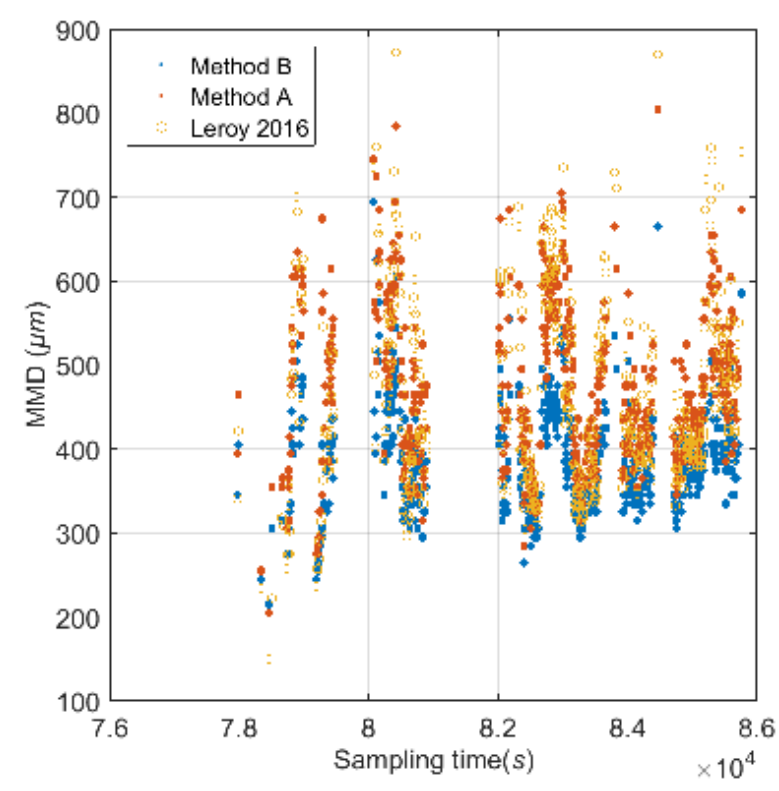

Figure 6. MMD time series

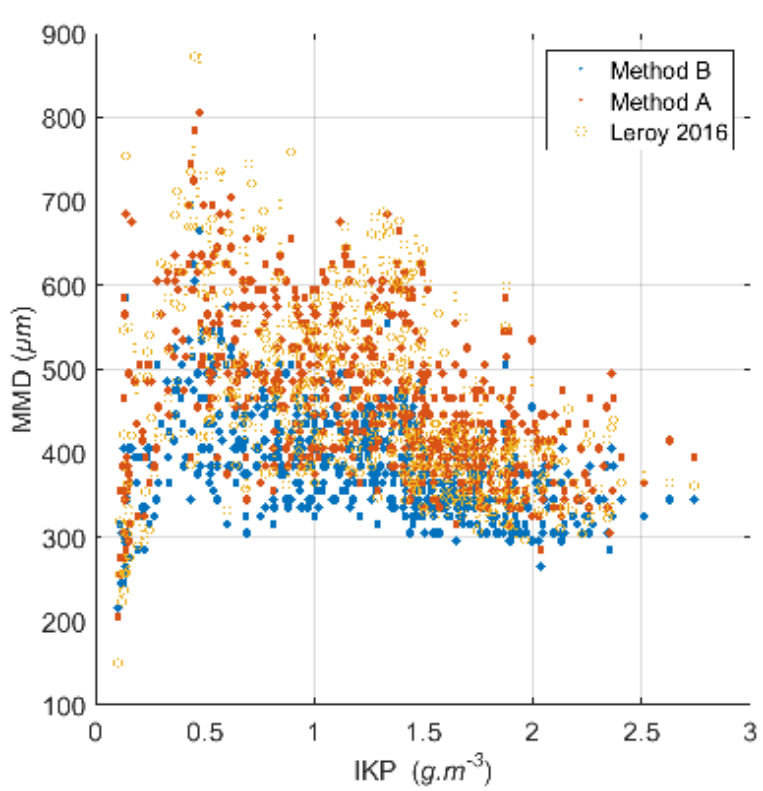

Figure 7. MMD as a function of measured IWC

The time series of Fig. 6 shows the MMD values retrieved along the flight path for Darwin \#16. The variations in the MMDs in the plot confirm that both methods detect considerable variability in ice particle population microphysical properties along the flight path in this oceanic MCS at approximately $-38^{\circ} \mathrm{C}$. As indicated in Table 2 (statistical values calculated from the 632 values of MMD retrieved for Darwin \#16), MMD calculated with Method A are found to vary between $205 \mu \mathrm{m}$ to $805 \mu \mathrm{m}$ and those retrieved with Method B vary between $215 \mu \mathrm{m}$ and 695 $\mu \mathrm{m}$. The largest range of possible MMD values is found when MMDs are calculated with the Leroy 2016 method, where MMD values vary between $150 \mu \mathrm{m}$ and $873 \mu \mathrm{m}$.

In Fig. 7, MMDs are plotted against the measured IKP-2 IWC. The results from all three methods reveal a general tendency for MMD values to decrease with increasing IWC, as already reported in ref. 8-9. Finally, the MMD retrieved from Method B are plotted against those of Method A in Fig. 8. Method B values are consistently about 20\% lower than those of Method A. As shown in Table 2, the MMD median and mean values are 385 and $386 \mu \mathrm{m}$ (Method B) and 455 and $469 \mu \mathrm{m}$ (Method A), respectively. The median and mean values calculated from the Leroy 2016 method are 430 and $458 \mu \mathrm{m}$, lying in between those of methods A and B. The choice of the mass retrieval method undeniably impacts the MMD values. On the one hand, MMDs calculated with Method B benefit from an effective density versus size relationship that arguably better accounts for ice cloud microphysical properties. On the other hand, MMD calculated with Leroy 2016 are based on dynamically produced $m-D$ relationships that are not averaged over time, but changes in effective density with size are in practice more limited due to the power law assumption. At this stage, it is hard to state which method yields the most accurate values

Table 2. Statistical values for the retrieved MMD.

\begin{tabular}{|c|c|c|c|c|c|c|c|}
\hline & \multicolumn{6}{|c|}{ Statistical values } \\
\hline & & Min & $25^{\text {th }}$ percent. & Median & Mean & $75^{\text {th }}$ percent. & Max \\
\hline \multirow{3}{*}{$\begin{array}{l}\overline{0} \\
\frac{1}{2} \\
\sum^{0}\end{array}$} & Leroy 2016 & 150 & 379 & 430 & 458 & 534 & 873 \\
\hline & Method A & 205 & 395 & 455 & 469 & 530 & 805 \\
\hline & Method B & 215 & 345 & 385 & 386 & 425 & 695 \\
\hline
\end{tabular}




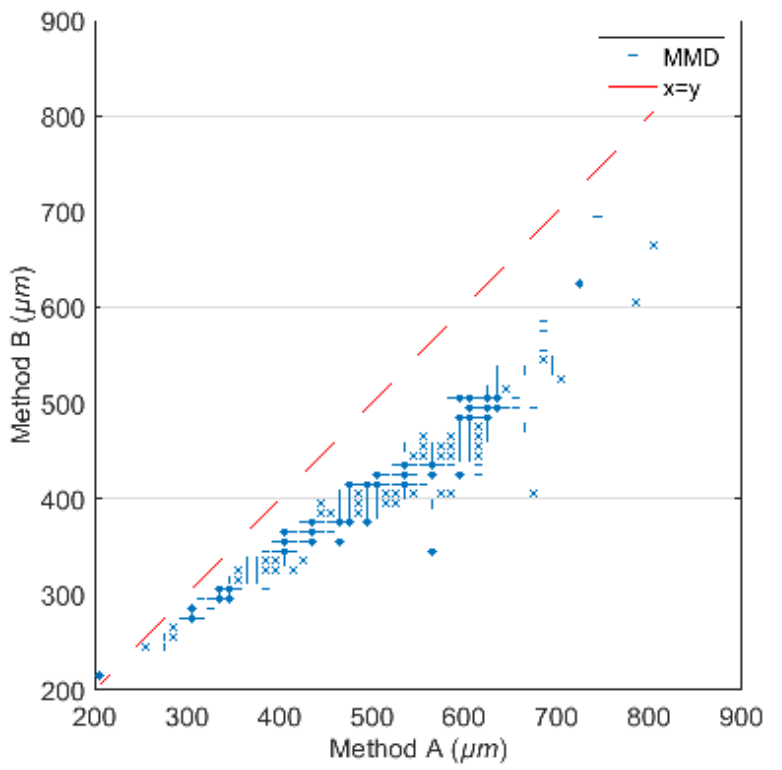

Figure 8. MMD values: comparison between methods $A$ and $B$
Ice particle properties are of fundamental importance in understanding the evolution and interactions of the microphysics of clouds. Measurement methods for the characterization of ice particle populations have not been fully developed by the atmospheric research community, and the variation of effective density with size is particularly poorly understood and has received little attention due to the complexity of the problem. This importance to fundamental atmospheric science research, and the key role of MMD values to these recent aviation applications underscores the need for further exploration of the new technique decribed in this article.

\section{Conclusion}

This paper presents a comparison between two techniques used to retrieve ice particle mass spectra and derived quantities from coincident and collocated PSD and independent bulk IWC in-situ measurements. Whereas the first method assumes a power law form for the mass-diameter relationship, an assumption that has been used for decades in the atmospheric sciences, the second method based on the inverse problem formulation leverages optimal use of the in-situ measurements to remove such specific functional constraints.. Both methods are tested on data from a single flight in an oceanic MCS with an IWC mean value in excess of $1.0 \mathrm{~g} . \mathrm{m}^{-3}$, sampled during the HAIC/HIWC Darwin-2014 flight campaign. Results reveal significant differences in PSD mass-related quantities retrieved by the two methods. First, the method based on the inverse problem formulation yields a much better agreement between calculated and independently measured IWC values, with the mean error decreased from $19 \%$ to $10 \%$. The choice of the retrieval method impacts the effective density, an important parameter used in ice accretion and particle trajectory models. Qualitatively the particle effective density with the second method, where there is no pre-determined functional form for density variations, was found to vary with size in a quite irregular manner with complexities not captured by the first method, where a regular polynominal decrease of density with size is imposed. MMD values were found to differ by $20 \%$ depending on the method, with the new method providing the lowest values. Further investigations are necessary in order to determine which method produces the more accurate mass spectra and derived MMD values, given their importance in aviation and general atmospheric science applications.

\section{Acknowledgments}

The research leading to these results has received funding from (i) the European Union's Seventh Framework Program in research, technological development and demonstration under grant agreement $\mathrm{n}^{\circ} \mathrm{ACP} 2-\mathrm{GA}-2012-$ 314314, (ii) the European Aviation Safety Agency (EASA) Research Program under service contract $n^{\circ}$ EASA.2013.FC27, and (iii) the Federal Aviation Administration (FAA), Aviation Research Division, and Aviation Weather Division, under agreement CON-I-1301 with the Centre National de la Recherche Scientifique. Funding to support the Darwin flight project was also provided by the NASA Aviation Safety Program, the Boeing Co., and Transport Canada. Additional support was also provided by Airbus SAS Operations, Science Engineering Associates, the Bureau of Meteorology, Environment Canada, the National Research Council of Canada and Universities of Utah and Illinois.

The authors thank the SAFIRE facility for the scientific airborne operations. SAFIRE (http://www.safire.fr) is a joint facility of CNRS, Météo-France and CNES dedicated to flying research aircraft. The authors greatly appreciate the provision of rapid-scan visible and infrared MTSAT-1R geostationary satellite data by the Japan Meteorological Agency through an agreement with the Bureau of Meteorology, and the processing and distributing of that data by the Bureau under the direction of R. Potts. The authors also acknowledge L. Nguyen, P. Minnis, and the NASA Langley Research Center team for further post-processing of the satellites images 


\section{References}

${ }^{1}$ Mason, J., W. Strapp, and P. Chow, "The ice particle threat to engines in flight", Proc. 44th AIAA Aerospace Sciences Meeting and Exhibit, Reno, NV, American Institute of Aeronautics and Astronautics, AIAA 2006-206. [Available online at http://arc.aiaa.org/doi/abs/10.2514/6.2006-206.], 2006.

${ }^{2}$ Lawson, L. J. Angus, and A. J. Heymsfield, "Cloud particle measurements in thunderstorm anvils and possible weather threat to aviation", J. Aircraft, 35, 113-121, doi:10.2514/2.2268, 1998.

${ }^{3}$ Mason, J. G., and M. Grzych, "The challenges identifying weather associated with jet engine ice crystal icing", SAE Tech. Paper 2011-38-0094, 12 pp., doi:10.4271/2011-38-0094, 2011.

${ }^{4}$ Grzych, M., and J. Mason, "Weather conditions associated with jet engine power-loss and damage due to ingestion of ice particles: What we've learned through 2009”, 14th Conf. on Aviation, Range and Aerospace Meteorology, Atlanta, GA, Amer. Meteor. Soc., 6.8. [Available online at https://ams.confex.com/ams/90annual/techprogram/paper_165923.htm.], 2010

${ }^{5}$ Mazzawy, Robert S., and Strapp J. Walter, “Appendix D - An Interim Icing Envelope : High Ice Crystal Concentrations and Glaciated Conditions", SAE Transactions, Journal of Aerospace, 116, 634-642, 2007.

${ }^{6}$ Dezitter, F.,A.Grandin, J.-L. Brenguier, F. Hervy, H. Schlager, P. Villedieu, and G. Zalamansky, "HAIC (High Altitude Ice Crystals)". Proc. Fifth AIAA Atmospheric and Space Environments Conf., San Diego, CA, American Institute of Aeronautics and Astronautics, AIAA 2013-2674. [Available online at http://arc.aiaa.org/doi/abs/10.2514/6.2013-2674.], 2013

${ }^{7}$ Strapp, J. W., G. A. Isaac. A. Korolev, T. Ratvasky, R. Potts, P. May, A. Protat, P. Minnis, A. Ackerman, A. Fridlind, J. Haggerty, and J. Riley, "The High Ice Water Content (HIWC) Study of deep convective clouds: Science and technical plan.”, FAA Rep. DOT/FAA/TC-14/31, available at http://www.tc.faa.gov/its/worldpac/techrpt/tc14-31.pdf. 105 pps, 2016.

${ }^{8}$ Leroy, D., E. Fontaine, A. Schwarzenboeck, J.W. Strapp, A. Korolev, G. McFarquhar, R. Dupuy, C. Gourbeyre, L. Lilie, A. Protat, J. Delanoe, F. Dezitter, and A. Grandin, "Ice Crystal Sizes in High Ice Water Content Clouds. Part II: Statistics of Mass Diameter Percentiles in Tropical Convection Observed during the HAIC/HIWC Project", J. Atmos. Oceanic Technol., 34, 117-136, doi: 10.1175/JTECH-D-15-0246.1, 2017.

${ }^{9}$ Leroy D., P. Coutris, E. Fontaine, A. Schwarzenboeck, J. W. Strapp, L. E. Lilie, A. Korolev, G. McFarquhar, F. Dezitter, and A. Grandin, "HAIC/HIWC field campaigns - Specific findings on ice crystals characteristics in high ice water content cloud regions", 8th AIAA Atmospheric and Space Environments Conference, AIAA AVIATION Forum, (AIAA 2016-4056) http://dx.doi.org/10.2514/6.2016-4056, 2016.

${ }^{10}$ Davison, C., J. MacLeod, and J. Strapp, "Naturally aspirating isokinetic total water content probe: Evaporator design and testing", 1st AIAA Atmospheric and Space Environments Conference, San Antonio, Texas, USA, American Institute of Aeronautics and Astronautics, doi:10.2514/6.2009-3861, 2009.

${ }^{11}$ Strapp, J. W., L. E. Lilie, T. P. Ratvasky, C. R. Davison, and C. Dumont, "Isokinetic TWC evaporator probe: Development of the IKP2 and performance testing for the HAIC-HAIC Darwin 2014 and Cayenne field campaigns", 8th AIAA Atmospheric and Space Environments Conference, Washington, D.C., USA, American Institute of Aeronautics and Astronautics, doi:10.2514/6.2016-4059, 2016.

${ }^{12}$ Lawson, R. P., D. O’Connor, P. Zmarzly, K. Weaver, B. Baker, Q. Mo, and H. Jonsson, "The 2D-S (Stereo) Probe: Design and Preliminary Tests of a New Airborne, High-Speed, High-Resolution Particle Imaging Probe", J. Atmospheric Ocean. Technol., 23, pp. 1462-1477, doi:10.1175/JTECH1927.1, 2006.

${ }^{13}$ Baumgardner, D., and Coauthors, "Airborne instruments to measure atmospheric aerosol particles, clouds and radiation: A cook's tour of mature and emerging technology" Atmospheric Research, Vol. 102, Oct. 2011, pp. 10-29, doi:10.1016/j.atmosres.2011.06.021.

${ }^{14}$ Leroy D., E. Fontaine, A. Schwarzenboeck, and J. Strapp, "Ice Crystal Sizes in High Ice Water Content Clouds. Part I: On the Computation of Median Mass Diameter from In Situ Measurements", J. Atmos. Oceanic Technol., 33, 2461-2476, doi: 10.1175/JTECH-D-15-0151.1, 2016.

${ }^{15}$ Coutris P., D. Leroy, E. Fontaine and A. Schwarzenboeck, "An inverse problem approach for the retrieval of ice particle mass from in-situ measurements”, Submitted to J. Atmos. Oceanic Technol., 2017

${ }^{16}$ Trontin P., G. Blanchard, and P. Villedieu "A comprehensive numerical model for mixed phase and glaciated icing conditions", In 8th AIAA Atmospheric and Space Environments Conference,Washington, DC, 13-17 June 2016. Paper AIAA2016-3742, 2016. 